\title{
Validity and reliability of a self-efficacy expectancy scale for adherence to antiretroviral therapy for parents and carers of children and adolescents with HIV/AIDS
}

\author{
Luciana Scarlazzari Costa, ${ }^{1}$ Maria do Rosário Dias de Oliveira Latorre, ${ }^{2}$ \\ Mariliza Henrique da Silva, ${ }^{3}$ Daniela Vinhas Bertolini, ${ }^{4}$ Daisy Maria Machado, ${ }^{5}$ \\ Sidnei Rana Pimentel, ${ }^{6}$ Heloísa Helena de Sousa Marques ${ }^{7}$
}

\begin{abstract}
Objective: To validate and evaluate the reproducibility of a self-efficacy (SE) scale for adherence to antiretroviral therapy in children and adolescents with HIV/AIDS, taking into account the perspective of parents/guardians.

Methods: The study was carried out at the Hospital-Dia, Centro de Referência e Treinamento em DST/AIDS (CRT/ SP), in São Paulo, Brazil. The parents/guardians of 54 children and adolescents aged 6 months to 20 years were interviewed during routine consultations at our service. Data on SE were collected using the Self-Efficacy for Following Anti-Retroviral Prescription Scale, and SE scores were calculated in two different ways: factor analysis and a predefined formula. The scale's internal consistency was verified using Cronbach's $\alpha$ coefficient. Validity was tested by comparing the mean scores of a group of patients who did adhere to antiretroviral treatment with those of a group that did not (Mann-Whitney test) and by calculating the Spearman correlation coefficient for agreement between scores and clinical parameters. Reproducibility was verified using the Wilcoxon test, intraclass correlation coefficients $\left(r_{\text {icc }}\right)$ and BlandAltman plots.
\end{abstract}

Results: The SE scale demonstrated good internal consistency $(\alpha=0.87)$ and good reproducibility $\left(r_{\text {icc }}=0.69\right.$ and $\left.r_{\text {icc }}=0.75\right)$. In terms of validity, the SE scale was capable of differentiating adherent patients from those who did not adhere to their antiretroviral treatment $(p=0.002)$ and exhibited a significant correlation with CD4 counts $(r=0.28$; $p=0.04)$.

Conclusions: The SE scale can be used to assess adherence to antiretroviral therapy in children and adolescents with HIV/AIDS, taking into account the perspective of parents/carers.

J Pediatr (Rio J). 2008;84(1):41-46: Scale, adherence, therapy, HIV, children, adolescent, reproducibility.

\section{Introduction}

The advent of antiretroviral medications and the Brazilian Ministry of Health's decision to provide them have retarded the progression of the disease and prolonged the survival of children who live with HIV/AIDS in the country, ${ }^{1}$ transforming infection with HIV into a chronic disease. ${ }^{2}$ This has allowed

1. Mestre, Universidade Estadual de Campinas (UNICAMP), Campinas, SP, Brazil. Doutoranda em Saúde Pública (Epidemiologia), Faculdade de Saúde Pública, Universidade de São Paulo (USP), São Paulo, SP, Brazil.

2. Professora titular, Departamento de Epidemiologia, Faculdade de Saúde Pública, USP, São Paulo, SP, Brazil. Doutora, Faculdade de Saúde Pública, USP, São Paulo, SP, Brazil.

3. Residência em Infectologia, Hospital Emílio Ribas, São Paulo, SP, Brazil. Diretora técnica de saúde, Hospital-Dia, Centro de Referência e Treinamento em DST/AIDS de São Paulo, São Paulo, SP, Brazil.

4. Residência em Infectopediatria, Instituto da Criança, Hospital das Clínicas, USP, São Paulo, SP, Brazil. Médico, Hospital-Dia, Centro de Referência e Treinamento em DST/AIDS de São Paulo, São Paulo, SP, Brazil.

5. Doutora. Professora afiliada, Departamento de Pediatria, Universidade Federal de São Paulo (UNIFESP), São Paulo, SP, Brazil. Hospital-Dia, Centro de Referência e Treinamento em DST/AIDS de São Paulo, São Paulo, SP, Brazil.

6. Residente em Infectologia, Hospital Emílio Ribas, São Paulo, SP, Brazil. Médico, Hospital-Dia, Centro de Referência e Treinamento em DST/AIDS de São Paulo, São Paulo, SP, Brazil.

7. Doutora, USP, São Paulo, SP, Brazil. Médica, Departamento de Pediatria, Instituto da Criança, Hospital das Clínicas, USP, São Paulo, SP, Brazil. Financial support: Fundação de Amparo à Pesquisa do Estado de São Paulo (FAPESP), protocol no. 04/00886-0. No conflicts of interest declared concerning the publication of this article.

Suggested citation: Costa LS, Latorre MR, da Silva MH, Bertolini DV, Machado DM, Pimentel SR, et al. Validity and reliability of a self-efficacy expectancy scale for adherence to antiretroviral therapy for parents and carers of children and adolescents with HIV/AIDS. J Pediatr (Rio J). 2008;84(1):41-46.

Manuscript received May 30 2007, accepted for publication Nov 192007.

doi:10.2223/JPED.1751 
many infected children to be currently reaching their adolescence. ${ }^{3}$ It is hoped that this increased survival is also associated with good quality of life.

One important issue related to the quality of life of patients with HIV/AIDS is its relationship with adherence to antiretroviral therapy. High power antiretroviral treatment, specifically Highly active combination antiretroviral therapy (HAART), has proven effective at reducing replication of the HIV virus and consequently at restoring immunity. ${ }^{4}$ As a result, opportunistic infections and mortality are reduced and patient survival and quality of life are improved. ${ }^{4}$ Nevertheless, many factors can affect the process of suppressing viral replication, including low potency of one of the drugs in the combination, viral resistance, the use of illicit drugs and inadequate compliance with treatment. ${ }^{2-4}$ According to Starace et al., ${ }^{5}$ the principal factor that contributes to the success of treatment is good adherence (above 95\%) to treatment. Irregular use, inadequate dosages or not following absorption routines, can increase the risk of virologic failure and viral resistance. $^{3}$

According to Shah, ${ }^{6}$ adherence to treatment can be defined as the capacity of the patient to follow the prescriptions of medications provided by the physician and, in the case of children, adherence depends as much on the behavior of parents/carers as on that of the child, in following the physician's recommendations.

Leite et al. ${ }^{7}$ developed a self-efficacy scale for adherence to antiretroviral therapy for adult patients with AIDS and with indications for antiretroviral treatment. This scale is based on Bandura's social cognitive theory ${ }^{8}$ which has been used to try to understand health protection behaviors. Self-efficacy is a person's own judgment of their ability to carry out a specific behavioral pattern with success - in the case of adherence, to follow the prescription regularly.

The use of questionnaires may be a fast and easy method of evaluating adherence to treatment. One important question when assessing children is, "Who to ask?"7,9 Although children are able to respond from a certain age onwards, it is their parents/carers who are the best informants, since children may be too young or too sick to respond. Furthermore, Eiser and Morse ${ }^{10}$ suggest that children cannot self-assess due to a lack of linguistic and cognitive development.

In the Brazilian context, to date, there is no specific instrument for evaluating adherence to antiretroviral therapy in children or adolescents living with HIV/AIDS. Therefore, the objective of this study is to validate and evaluate the reproducibility of the scale proposed by Leite et al., ${ }^{7}$ from the perspective of the parents/carers of children and adolescents living with HIV/AIDS.

\section{Methods}

The study was conducted between March 27th and August 20th, 2005, at the Hospital-Dia, Centro de Referência e Treinamento em DST/AIDS (CRT/SP - Reference and Training
Center for STD/AIDS) in São Paulo, SP, Brazil. The study enrolled children and adolescents aged 6 months to 20 years.

The sample size was calculated assuming a variation in Cronbach's alpha coefficient of around 0.68 to 0.94 . Assuming $\alpha=5 \%$ and $\beta=10 \%$, it was estimated that 25 children with HIV/AIDS would be needed for the validation phase.

It proved possible to contact the parents/guardians of 96 of the 134 patients registered at the CRT $(71.6 \%)$. Of these, $6.3 \%$ refused to take part, and it was possible to interview 90 ( $67.2 \%$ of the study population). Of the 90 children/ adolescents who agreed to enroll on the study, 54 were taking antiretrovirals and were invited to take part in this study.

In order to assess reproducibility, 43 parents/guardians were interviewed a second time at consultations that were set for 30 to 45 days after the first interview. The remaining 11 did not attend when requested.

This research project was approved by the Research Ethics Committee at the Public Health Faculty at the Universidade de São Paulo (COEP-FSP) and by the Ethics Commission at the Centro de Referência e Treinamento em STD/AIDS.

\section{Self-efficacy scale for following antiretroviral prescription (SE)}

The scale comprises 21 situations in which the patient indicates whether they would manage to take the antiretroviral medications prescribed by their physician. ${ }^{3}$ Available answers are: 0 - I definitely won't take them, 1 - I don't think I'll take them, 2 - don't know, 3 - I think I'll take them and 4 - I definitely will take them.

Scores can be calculated in two ways:

1) SE score 1. The first method is via exploratory factor analysis using principal component analysis to extract factors, varimax rotation, selection of factors with a KMO (Kaiser-Meyer-Olkin) $>1$ and correlation coefficient, 0.30. Only the first factor was accepted. In this analysis a coefficient of regression was estimated for each question and the self-efficacy score was calculated from the sum of the products between the question and its respective coefficient of regression $\left(\sum_{i=1 \text { to21 }}\left(\beta \mathrm{i}^{*} \mathrm{Ai}\right)\right)$, where $\beta \mathrm{i}$ is the parameter/coefficient of regression and $\mathrm{A} i$ is the question from the self-efficacy questionnaire ( $i=1$ to 21 ). Finally, this score was standardized by transformation into a $\mathrm{z}$ score. The standardized score is a continuous quantitative variable that can vary from -1 to 1 .

2) SE score 2. The second method is to sum the values attributed to the replies to the 21 questions, subtract from this the minimum value assumed by the scale (in this case, zero), divide by the amplitude of the scale (84-0) and then multiply by 100 . This score is a continuous quantitative variable that can vary from 0 to 100 . 


\section{Analysis of data}

For the descriptive analysis of the SE scores, means, standard deviations, and minimum and maximum values were calculated in addition to the test of adherence to the normal distribution curve (Kolmogorov-Smirnov test). Proportions were calculated for qualitative variables.

Internal consistency was analyzed using Cronbach's alpha coefficient. A questionnaire is considered to have good internal consistency when $\alpha$ is greater than $0.70 .{ }^{11}$

Validation employed the following strategies:

1) SE scores were compared between the adherent group (mean percentage adherence greater than or equal to $95 \%$ ) and the group that did not adhere (mean percentage less than $95 \%$ ) to antiretroviral treatment. The MannWhitney test was used.

2) The SE scores were correlated with clinical markers - CD4 defender cell counts and viral load, using the Spearman correlation coefficient. The variables CD4 and viral load were log-transformed.

The reproducibility of the questionnaires was tested by comparing the mean scores from the two different dates (testretest). The intraclass correlation coefficient $\left(r_{\text {icc }}\right)$ was also calculated and a Bland-Altman plot produced. ${ }^{12}$

\section{Results}

More than $85 \%$ of the people who responded to the survey were parents (father/mother, adoptive parents) and $71.2 \%$ of these were mothers (biological or adoptive). Just $15 \%$ of the interviewees were the aunts/uncles/grandparents of the children/adolescents.

The internal consistency of score 1 was 0.88 , and for the sum of the questions (score 2 ) it was 0.87 , demonstrating excellent internal consistency. The test of adherence to the normal curve demonstrated that neither SE score 1 nor SE score 2 have normal distribution ( $p=0.005$ and $p=0.017$, respectively).

The factor analysis selected a single factor which explained $31.34 \%$ of the accumulated variance (Table 1 ). Score 1 was calculated based on the regression coefficients listed in Table 1. It will be noted that questions 4, 5, 10, 13 and 20 were not selected for the score calculation since they had $r<$ 0.30 , i.e., they had a weak correlation with the model proposed.

The comparison of SE scores 1 and 2 between the groups of children who were and were not adherent to the antiretroviral treatment regime demonstrated that the means of scores 1 and 2 for self-efficacy were higher among those in the group adherent to treatment than among those in the group that was noncompliant and that these differences were statistically significant $(0.20 \times-0.97 ; p=0.002$ for score 1 and 92.22 $x$ 78.70; $p=0.002$ for score 2 ) (Table 2 ).
The analysis of the correlation between scores 1 and 2 and clinical characteristics indicated a statistically significant correlation between score 2 and CD4 ( $r=0.28 ; p=0.040)$, while the correlation between score 1 and CD4 was close to statistical significance $(r=0.26 ; p=0.061$ ) (data not shown). With relation to viral load, the analysis was carried out for 34 patients, since in 20 cases the viral load was undetectable. The correlation coefficients for self-efficacy scores 1 and 2 exhibit a descending tendency (negative), although this is not statistically significant (data not shown).

The analysis of reproducibility demonstrated that, for SE score 1 (Table 3 ), no statistically significant difference was detected between test and retest. When score 2 is analyzed, a significant difference was found between means for test and retest $(89.70 \times 92.47 ; \mathrm{p}=0.018)$.

Table 3 also lists the intraclass correlation coefficients for SE scores 1 and 2 for test and retest. The correlation coefficients for both score 1 and score 2 were significant, at 0.69 and 0.75 , respectively, demonstrating good reproducibility of the questionnaire to determine self-efficacy for following antiretroviral prescriptions.

The Bland-Altman plot (Figure 1) demonstrated good agreement between test and retest for self-efficacy.

All of the analyses for validation and reproducibility testing were also performed for the sample broken down into three age groups ( 6 months to 4 years, 5 to 11 years and 12 to 20 years) and the results proved similar to those described for the sample as a whole.

\section{Discussion}

The objective of this study was to validate, for children and adolescents and taking the perspective of their parents/ carers into account, and also to test the reproducibility of, an antiretroviral therapy adherence scale that was proposed by Leite et al. ${ }^{7}$ for adult patients with HIV/AIDS. The scale was adapted so that the parents/carers replied on behalf of the children/adolescents.

The fact that parents/carers responded on the behalf of the children/adolescents could be considered a limitation of this study. However, the lack of linguistic and cognitive development could be an impediment to self-assessment and the recommendation is that it should be the parents/guardians/ carers who live with these children/adolescents who speak for them. ${ }^{9,10}$ According to Eiser \& Morse ${ }^{10}$ there may be distortions between the responses of parents and children, but these tend to diminish with age, since, as verbal abilities develop, the child becomes better able to describe experiences and emotions to parents/carers. In this study it was decided to use the point of view of the parents/carers, since this is the recommendation when working with children/adolescents. 
Table 1 - Factor analysis of the efficacy score (CRT/SP, March 2005)

\begin{tabular}{|c|c|c|c|}
\hline Items on scale & Code & Factor 1 & $\begin{array}{l}\text { Regression } \\
\text { coefficients }\end{array}$ \\
\hline If the child/adolescent is in good health? & SE1 & 0.490 & 0.075 \\
\hline $\begin{array}{l}\text { If there is so little virus in the child/adolescent's blood } \\
\text { that it does not appear in the viral load? }\end{array}$ & SE2 & 0.718 & 0.109 \\
\hline If the child/adolescent is depressed and feeling down? & SE3 & 0.719 & 0.109 \\
\hline $\begin{array}{l}\text { If the child/adolescent was discriminated against or } \\
\text { rejected? }\end{array}$ & SE4 & Not selected & Not selected \\
\hline If the child/adolescent was occupied and having fun? & SE5 & Not selected & Not selected \\
\hline $\begin{array}{l}\text { If the child/adolescent was traveling for leisure or } \\
\text { work? }\end{array}$ & SE6 & 0.476 & 0.072 \\
\hline If the child/adolescent was out? & SE7 & 0.688 & 0.104 \\
\hline If the child/adolescent was feeling ill? & SE8 & 0.632 & 0.096 \\
\hline $\begin{array}{l}\text { If the child/adolescent was with someone that you } \\
\text { didn't want to know that they have the AIDS virus? }\end{array}$ & SE9 & 0.703 & 0.107 \\
\hline If the child/adolescent had to take lots of pills? & SE10 & Not selected & Not selected \\
\hline If the child/adolescent was nervous or irritated? & SE11 & 0.683 & 0.104 \\
\hline $\begin{array}{l}\text { If the physician who treats the child/adolescent } \\
\text { changes often? }\end{array}$ & SE12 & 0.567 & 0.086 \\
\hline $\begin{array}{l}\text { If the child/adolescent had to take medicine many } \\
\text { times a day? }\end{array}$ & SE13 & Not selected & Not selected \\
\hline If the child/adolescent was with strangers? & SE14 & 0.758 & 0.115 \\
\hline If the medicine was hard to swallow? & SE15 & 0.549 & 0.083 \\
\hline If it was a holiday or weekend? & SE16 & 0.667 & 0.101 \\
\hline $\begin{array}{l}\text { If the child/adolescent had to change the times they } \\
\text { ate and slept? }\end{array}$ & SE17 & 0.529 & 0.080 \\
\hline If the medicine had a bad taste or strong smell? & SE18 & 0.462 & 0.070 \\
\hline $\begin{array}{l}\text { If the child/adolescent had been doing things out of } \\
\text { routine? }\end{array}$ & SE19 & 0.666 & 0.101 \\
\hline $\begin{array}{l}\text { If the child/adolescent was with someone who doesn't } \\
\text { think it's worth taking this medicine? }\end{array}$ & SE20 & Not selected & Not selected \\
\hline If the medicine has bad effects? & SE21 & 0.677 & 0.103 \\
\hline$\%$ of accumulated variance & & 31.341 & - \\
\hline Cronbach's alpha for all items/questions & & 0.875 & - \\
\hline
\end{tabular}

CRT/SP = Centro de Referência e Treinamento em DST/AIDS de São Paulo.

Although losses did occur, it is not believed that there was selection bias due to losses, since the majority of people who presented at consultations were interviewed (93.8\%). Of the 38 patients who did not enter the study, 35 were not even consulting routinely at the service, because either they were frequent absentees or they had moved to other cities. Therefore, the possibility that only those who were more interested participated can be ruled out.

The good internal consistency of the SE scale for the whole sample of children and adolescents (alpha $=0.87$ ) is evidence of a high correlation between the items on the scale, 
Table 2 - Comparison of mean self-efficacy scores by patients who were nor were not adherent to antiretroviral treatment (CRT/SP, March 2005)

\begin{tabular}{lccc}
\hline Auto-Efficacy Scores & $\mathbf{n}$ & Mean (SD) & p* \\
\hline Score 1 & & & \\
$\quad$ Adherent & 45 & $0.20(0.77)$ & 0.002 \\
$\quad$ Not adherent & 9 & $-0.97(1.45)$ & \\
Score 2 & & $92.22(10.77)$ & 0.002 \\
$\quad$ Adherent & 45 & $78.70(14.60)$ & \\
$\quad$ Not adherent & 9 &
\end{tabular}

CRT/SP = Centro de Referência e Treinamento em DST/AIDS de São Paulo; SD = standard deviation.

* Mann-Whitney test.

suggesting that it is reliable for measuring self-efficacy in children and adolescents with HIV/AIDS, taking into consideration the perspective of parents/carers. Cronbach's alpha for the whole sample was similar to that found in the study carried out by Leite et al. ${ }^{7}$

When the scale was subjected to factor analysis, a single factor was identified that explained $31 \%$ of accumulated variance. In this analysis the standardization of the self-efficacy score was generated. In the study by Leite et al., ${ }^{7}$ the factor analysis identified a single factor that explained more than $50 \%$ of the accumulated variance and generated the standardized self-efficacy score. It is concluded that the results of the factor analysis are similar to those of the study that validated the self-efficacy scale.

The SE scale was able to differentiate children/adolescents who were adherent to antiretroviral treatment from those who were not adherent, whether using score 1 or score 2 . With both versions of the score, mean self-efficacy was lower among non-adherent patients, when compared with compliant patients. These findings suggest that the children/ adolescents who were adherent to their antiretroviral treatment had a greater expectation of self-efficacy than those who were not adherent. These results are similar to those found by the original study that first described the scale. $^{3}$
The authors of the self-efficacy scale did not correlate it with clinical parameters, but such an analysis was carried out here.

Compatible with the hypothesis that patients who are compliant with their antiretroviral treatment have a good response and reduce their viral load while increasing CD4 cell levels, ${ }^{10,11}$ scores 1 and 2 for self-efficacy correlated with the CD4 counts (respectively, $p=0.061$ and $p=0.040$ ), indicating good response to antiretroviral treatment.

The analysis of the reproducibility of the SE scale had also not been previously undertaken, since the study that generated the scale did not analyze this aspect. There was no statistically significant difference in the mean of score 1 when the first and second interview results were compared, whereas score 2 exhibited a statistically significant difference between the means for the two interviews. This difference was caused by two patients' self-efficacy scores that were $65 \%$ and $89 \%$ at the first interview and $95 \%$ and $100 \%$ at the second.

The intraclass correlation coefficients for SE scores 1 and 2 were statistically significant both for the sample as a whole and for different age group subsets. These results show that both remained stable for the two interviews, thereby demonstrating good reproducibility.

In conclusion, the SE scale exhibited good internal consistency and good reproducibility for this sample of children and

Table 3 - Test-retest comparison between self-efficacy and intraclass correlation coefficients (CRT/SP, March 2005)

\begin{tabular}{lcccccc}
\hline Score & $\mathbf{n}$ & $\begin{array}{c}\text { Test } \\
\text { Mean (SD) }\end{array}$ & $\begin{array}{c}\text { Retest } \\
\text { Mean (SD) }\end{array}$ & $\mathbf{p *}$ & $\mathbf{r}_{\text {icc }}$ & $\mathbf{p}$ \\
\hline Score 1 & 43 & $0.01(0.89)$ & $0.00(1.00)$ & 0.828 & 0.69 & $<0.001$ \\
Score 2 & 43 & $89.70(11.83)$ & $92.47(10.07)$ & 0.018 & 0.75 & $<0.001$ \\
\hline
\end{tabular}

CRT/SP = Centro de Referência e Treinamento em DST/AIDS de São Paulo; $r_{\text {icc }}=$ intraclass correlation coefficient; SD = standard deviation.

* Wilcoxon test. 

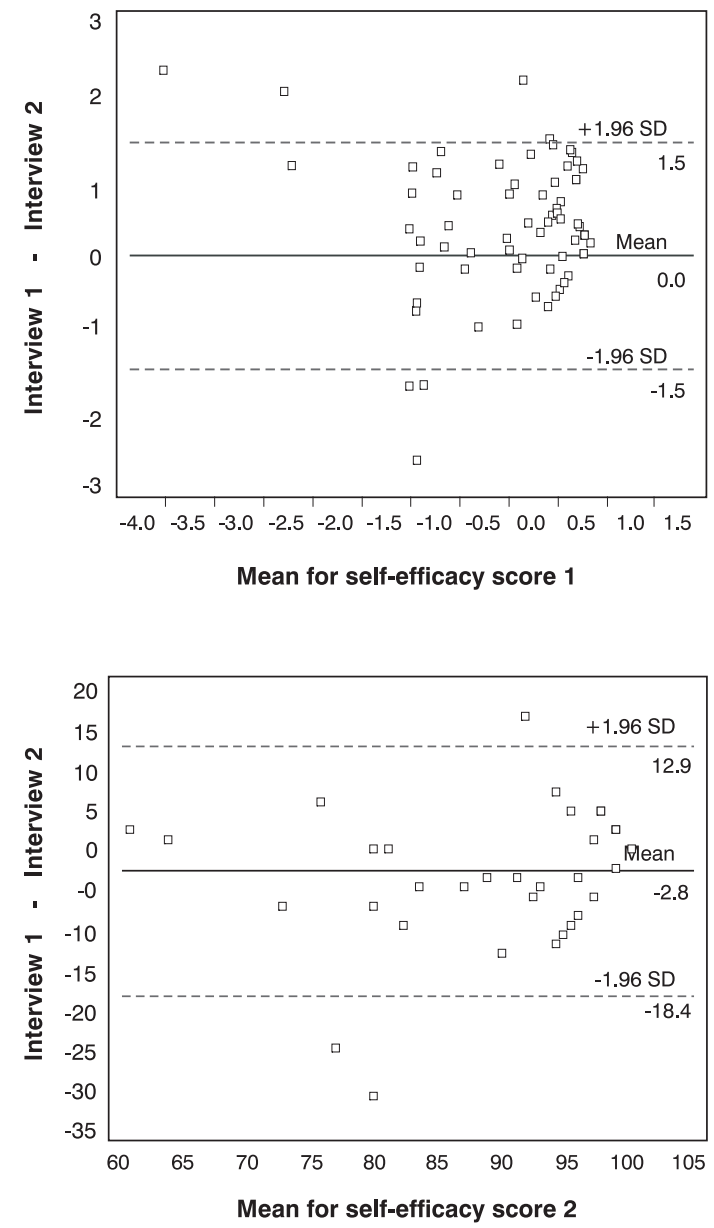

$\mathrm{SE}=$ self-efficacy

Figure 1 - Bland-Altman plot showing score 1 (a) and score 2 (b) for self-efficacy

adolescents with HIV/AIDS and can be used to identify patients with greater risk of not adhering to their antiretroviral therapy.

It is suggested that, for routine clinical use, the score labeled here score 2 should be used, since it is calculated from a predefined and easily-applicable formula. In contrast, score 1 - which was estimated using factor analysis - is a score made up of the questions that best correlate with it, and it is necessary for the investigator to have familiarity with factor analysis in addition to a statistical software package.

\section{References}

1. Matida LH, da Silva MH, Tayra A, Succi RC, Gianna MC, Gonçalves $A$, et al. Prevention of mother-to-child transmission of HIV in São Paulo State, Brazil: an update. AIDS. 2005;19 suppl 4: S37-41.
2. Gibb DM, Goodall RL, Giacomet V, McGee L, Compagnucci A, Lyall $\mathrm{H}$; Paediatric European Network for Treatment of Aids Steering Committee. Adherence to prescribed antiretroviral therapy in human immunodeficiency virus-infected children in the PENTA 5 trial. Pediatr Infect Dis J. 2003;22:56-62.

3. Pluciennik AM. Transmissão materno infantil do vírus da imunodeficiência humana adquirida: quanto custa não prevenir [tese]. São Paulo: Faculdade de Saúde Pública da USP; 2003.

4. Dyke RBV, Lee S, Johnson GM, Wiznia A, Mohan K, Stanley K, et al. Reported adherence as a determinant of response to highly active antiretroviral therapy in children who have human immunodeficiency virus infection. Pediatrics. 2002;109(4):1-7.

5. Starace F, Massa A, Amico KR, Fisher JD. Adherence to antiretroviral therapy: an empirical test of the informationmotivation-behavioral skills model. Health Psychol. 2006; 25:153-62.

6. Shah CA. Adherence to high activity antiretroviral therapy (HAART) in pediatric patients infected with HIV: issues and interventions. Indian J Pediatr. 2007;74:55-60.

7. Leite JC, Drachler ML, Centeno MO, Pinheiro CA, Silveira VL. Desenvolvimento de uma escala de auto-eficácia para adesão ao tratamento anti-retroviral. Psicol Reflex Crit. 2002;15:12133.

8. Bandura A. Self-efficacy: toward a unifying theory of behavioral change. Psychol Rev. 1977;84:191-215.

9. Gortmaker SL, Lenderking WR, Clark C, Lee S, Fowler MG, Oleske JM; The ACTG 219 Team. Development and use of a pediatric quality of life questionnaire in AIDS clinical trials: reliability and validity of the general health assessment for children. In: Drotar D. Measuring health-related quality of life in children and adolescents: implications for research and practice. Mahwah, NJ: Lawrence Erlbaum Associates; 1998. p. 219-35.

10. Eiser C, Morse R. Quality-of-life measures in chronic diseases of childhood. Health Technol Assess. 2001;5:1-95.

11. Streiner DL, Norman GR. Health measurement scales: a practical guide to their development and use. 3rd ed. Oxford: Oxford University Press; 2003.

12. Drotar D, Levi R. Critical issues and needs in health-related quality of life assessment of children and adolescents with chronic health condition. In: Drotar D. Measuring health-related quality of life in children and adolescents: implications for research and practice. Mahwah, NJ: Lawrence Erlbaum Associates; 1998. p. 3-23.

Correspondence:

Maria do Rosário Dias de Oliveira Latorre

Departamento de Epidemiologia

Faculdade de Saúde Pública - USP

Av. Dr. Arnaldo, 715

CEP 01246-904 - São Paulo, SP - Brazil

Tel.: +55 (11) 3066-7744

E-mail: mdrddola@usp.br 